\title{
Enhanced Interfacial Properties of Electrochemically Deposited ZnO Nano Structured Electrode
}

\author{
K. Selvarani. $K^{1}$, ShamimaHussain ${ }^{2}$, R. Prasanth ${ }^{1, *}$ \\ ${ }^{1}$ UNESCOMadanjeet School of Green Energy Technology, Pondicherry University \\ ${ }^{2}$ UGC - DAE Consortium for Scientific Research, Pondicherry, India, 605014. \\ E-mail: prasanth.get@pondiuni.edu.in
}

doi: $10.20964 / 2017.07 .31$

Received: 13 March 2017 / Accepted: 30 April 2017 / Published: 12 June 2017

The electronic properties at the transparent conducting oxide (TCO)/ semiconductor interface are crucial in optimizing the efficiency of light harvesting and storage devices. The back scattered current and surface defects of $\mathrm{ZnO}$ nanorods at interface limit the commercial level fabrication of device structures with this material system. Herein, a cost effective and scalable electro-nanofabrication technique has been utilized for the growth of $\mathrm{ZnO}$ nanorods over seeded $\mathrm{TCO}$ substrates. The electrochemical conditions for controlling $\mathrm{ZnO}$ nano rod morphology over the $\mathrm{ZnO}$ self-seeded transparent conducting oxide coated glass substrate are comprehensively investigated. The results show that the seed layer thickness, annealing environment for seeding and growth as well as processing temperatures are critical in optimizing the electronic properties at the interface. By controlling these parameters the back scattering current has been reduced to record minimum of $10^{-7} \mathrm{~A}$ and the interfacial resistance has been minimized to $30 \Omega$. Photoluminescence spectroscopy and the Electrochemical Impedance spectroscopy are effectively used in this study for defect center analysis and interfacial characterization.

Keywords: $\mathrm{ZnO}$ nanorods, Electro deposition, interfacial resistance, back scattering current

\section{$\underline{\text { FULL TEXT }}$}

(C) 2017 The Authors. Published by ESG (www.electrochemsci.org). This article is an open access article distributed under the terms and conditions of the Creative Commons Attribution license (http://creativecommons.org/licenses/by/4.0/). 